Pacific Journal of Mathematics

BISECTION INTO SMALL ANNULI

az and MITSURU Nara 


\section{BISECTION INTO SMALL ANNULI}

\section{Moses Glasner, Richard Katz, aNd Mitsuru NaKai}

In a Riemannian manifold the modulus of a relatively compact set with border consisting of two sets of components is introduced to measure its magnitude from the viewpoint of harmonic functions. The existence of a subdivision into two sets each having modulus arbitrarily close to one is established.

1. Let $M$ be a Riemannian manifold, i.e. a connected orientable $C^{\infty}$ $n$-manifold that carries a metric tensor $g_{i j}$. Consider a bordered compact region $E \subset M$ whose border is the union of two nonempty disjoint sets $\alpha$ and $\beta$ of components. We shall call the configuration $(E, \alpha, \beta)$ an annulus.

Let $h$ be the harmonic function on $E$ with continuous boundary values 0 on $\alpha$ and $\log \mu>0$ on $\beta$ such that

$$
\int_{\alpha} * d h=2 \pi \text {. }
$$

The number $\mu>1$ is called the modulus of the annulus $(E, \alpha, \beta)$ and we set

$$
\mu=\bmod (E, \alpha, \beta) .
$$

Let $w$ be the harmonic measure of $\beta$ with respect to $E$, i.e. the harmonic function on $E$ with continuous boundary values 0 on $\alpha$ and 1 on $\beta$. By using Green's formula we obtain

$$
\log \mu=\frac{2 \pi}{D_{E}(w)},
$$

where $D_{E}(w)$ denotes the Dirichlet integral $\int_{E} d w \wedge * d w$ of $w$ over $E$.

An illustration of these concepts is obtained by taking the annulus $E=\{x|r \leqq| x \mid \leqq R\}$ in $n$-dimensional $(n \geqq 3)$ Euclidean space. The harmonic measure of $|x|=R$ with respect to $E$ is

$$
w=\frac{|x|^{2-n}-r^{2-n}}{R^{2-n}-r^{2-n}}
$$

and the modulus of $(E,|x|=r,|x|=R)$ is given by

$$
\log \mu=\pi^{1-(n / 2)}(2-n) \Gamma\left(\frac{n}{2}\right)\left(R^{2-n}-r^{2-n}\right) .
$$

Note that $\mu>1$, in a sense, measures the relative thickness of $E$ and that $\mu \rightarrow 1$ as $R-r \rightarrow 0$. 
Our result gains interest if we generalize the notion of annulus slightly. Let $\left(E_{j}, \alpha_{j}, \beta_{j}\right)(j=1, \cdots, m)$ be annuli such that $E_{i} \cap E_{j}=\varnothing$ for $i \neq j$. Set $E=\bigcup_{j=1}^{m} E_{j}, \alpha=\bigcup_{j=1}^{m} \alpha_{j}, \beta=\bigcup_{j=1}^{m} \beta_{j}$. Then we shall also call the configuration $(E, \alpha, \beta)$ an annulus. The modulus $\mu=\bmod (E, \alpha, \beta)$ and the harmonic measure of $E$ with respect to $\beta$ are defined exactly as for a connected annulus. Moreover, formula (2) is valid and consequently we have

$$
\frac{1}{\log \mu}=\sum_{j=1}^{m} \frac{1}{\log \mu_{j}}
$$

where $\mu_{j}=\bmod \left(E_{j}, \alpha_{j}, \beta_{j}\right)$.

2. Let $M$ be a noncompact Riemannian manifold throughout this number. A function which is positive and harmonic on $M$ except for a fundamental singularity is called a Green's function if it majorizes no nonconstant positive harmonic functions on $M$. If a Green's functions exists, then $M$ is called hyperbolic; otherwise it is called parabolic.

An increasing sequence $\left(\Omega_{n}\right)$ of bordered compact regions is called an exhaustion of $M$ if $\cup \Omega_{n}=M$. Note that the configuration $\left(\Omega_{n+1}-\bar{\Omega}_{n}, \partial \Omega_{n}, \partial \Omega_{n+1}\right)$ is an annulus and denote its modulus by $\mu_{n}$.

The parabolicity of a noncompact Riemannian manifold $M$ is characterized by the following

Modular CRITERION. There exists an exhaustion $\left(\Omega_{n}\right)$ of $M$ with $\Pi \mu_{n}=\infty$ if and only if $M$ is parabolic.

In the 2-dimensional case this criterion has been established by Sario [5] and Noshiro [4] and their work can easily be generalized to arbitrary Riemannian manifolds (cf. Smith [7], Glasner [2]).

One naturally asks whether a convergent modular product has any bearing on the hyperbolicity of a manifold. The main result of this paper is that any annulus can be separated into two annuli each having modulus less than $1+\varepsilon$. This clearly answers the question in the negative and also settles Problem 3 in Sario [6].

3. Suppose the annulus $(E, \alpha, \beta)$ has components $\left(E_{j}, \alpha_{j}, \beta_{j}\right)$ $(j=1, \cdots, m)$. Let $\gamma_{j}$ be a hypersurface in $E_{j}$ such that $E_{j}-\gamma_{j}=$ $E_{j}^{\prime} \cup E_{j}^{\prime \prime}, E_{j}^{\prime} \cap E_{j}^{\prime \prime}=\varnothing$, and $\left(E_{j}^{\prime}, \alpha_{j}, \gamma_{j}\right)$ and $\left(E_{j}^{\prime \prime}, \gamma_{j}, \beta_{j}\right)$ are annuli. Set $\gamma=\bigcup_{j=1}^{m} \gamma_{j}$. We shall call $\gamma$ a bisecting surface of $(E, \alpha, \beta)$. Also set $E^{\prime}=\bigcup_{j=1}^{m} E_{j}^{\prime}$ and $E^{\prime \prime}=\bigcup_{j=1}^{m} E_{j}^{\prime \prime}$. We are now able to state the

Theorem. Given an annulus $(E, \alpha, \beta)$ and $\varepsilon>0$ there exists $a$ bisecting surface $\gamma$ of $(E, \alpha, \beta)$ such that 


$$
\bmod \left(E^{\prime}, \alpha, \gamma\right)<1+\varepsilon, \bmod \left(E^{\prime \prime}, \gamma, \beta\right)<1+\varepsilon .
$$

This was established by Sario [5] for doubly connected plane regions using Koebe's distortion theorem. All proofs for the 2-dimensional case known to the authors use either a distortion theorem, in essence, or an estimate (cf. Akaza-Kuroda [1]) obtained by means of Möbius transformations (Nakai-Sario [3]) which cannot be generalized to higher dimensions. Therefore, one is led to estimate the Dirichlet integral of the harmonic measure directly and the proof presented here seems to even give a more elementary proof for the 2-dimensional case.

4. Denote by $C(a, b)=C_{x_{0}}(a, b)$ the Euclidean cylinder

$$
\sum_{j=1}^{n-1}\left(x^{i}-x_{0}^{i}\right)^{2}<a^{2}, x_{0}^{n}<x^{n}<x_{0}^{n}+b,
$$

where $a, b>0$ and $x_{0}=\left(x_{0}^{1}, \cdots, x_{0}^{n}\right)$ is a fixed point. Let $\mathfrak{F}(a, b)$ be the class of $C^{1}$ functions $f$ on $C(a, b)$ with continuous boundary values 0 on $\overline{C(a, b)} \cap\left\{x^{n}=x_{0}^{n}\right\}$ and 1 on $\overline{C(a, b)} \cap\left\{x^{n}=x_{0}^{n}+b\right\}$. Also denote by $D^{e}$ the Dirichlet integral with respect to the Euclidean metric. We set $s$ equal to the surface area of $\sum_{i=1}^{n-1}\left(x^{i}\right)^{2}=1, x^{n}=0$ and state the

Lemma. For every $f \in \mathfrak{F}(a, b)$,

$$
D_{C(a, b)}^{e}(f) \geqq \frac{s a^{n-1}}{b}
$$

and equality holds for $f_{0}(x)=b^{-1}\left(x^{n}-x_{0}^{n}\right)$.

Clearly (6) is valid with equality for $f_{0}$. To prove (6) for an arbitrary $f$ we may assume $f \in C^{1}$ in a neighborhood of $\overline{C(a, b)}$. By Green's formula we have

$$
D_{C(a, b)}^{e}\left(f-f_{0}, f_{0}\right)=\int_{\partial C(a, b)}\left(f-f_{0}\right) \frac{\partial f_{0}}{\partial n} d s=0,
$$

since $f-f_{0}=0$ on the upper and lower boundary of the cylinder and $\left(\partial f_{0} / \partial n\right)=0$ on the side of the cylinder. Consequently Schwarz's inequality yields

$$
D_{C(a, b)}^{e}(f) \cdot D_{C(a, b)}^{e}\left(f_{0}\right) \geqq\left(D_{C\langle a, b)}^{e}\left(f, f_{0}\right)\right)^{2}=\left(D_{C(a, b)}^{e}\left(f_{0}\right)\right)^{2},
$$

which completes the proof.

5. We are ready to prove the main result. Take a point $x_{0} \in \alpha$ and a point $y_{0} \in \beta$. Let $x^{1}, \cdots, x^{n}$ be a local coordinate system at 
$x_{0}=\left(x_{0}^{1}, \cdots, x_{0}^{n}\right)$ valid in a neighborhood $U$ of $x_{0}$ such that $U \cap \alpha$ is given by $x^{n}=x_{0}^{n}$ and $x^{n}$ increases as $x$ moves from $\alpha$ to $E$. Similarly, let $y^{1}, \cdots, y^{n}$ be a local coordinate system at $y_{0}=\left(y_{0}^{1}, \cdots, y_{0}^{n}\right)$ valid in a neighborhood $V$ of $y_{0}$ such that $V \cap \beta$ is given by $y^{n}=y_{0}^{n}$ and $y^{n}$ increases as $y$ moves from $\beta$ to $E$. Choose a constant $c>0$ so small that

$$
\sqrt{g} \mid U \cup V>\sqrt{c}
$$

and also

$$
\left(g^{i j} \mid U \cup V\right) \xi_{i} \xi_{j} \geqq \sqrt{c} \sum_{i=1}^{n}\left(\xi_{i}\right)^{2}
$$

for every vector $\left(\xi_{1}, \cdots, \xi_{n}\right)$. Now choose $a>0$ sufficiently small to insure that $\sum_{i=1}^{n-1}\left(x^{i}-x_{0}^{i}\right)<a^{2}$ with $x^{n}=x_{0}^{n}$ and $\sum_{i=1}^{n-1}\left(y^{i}-y_{0}^{i}\right)^{2}<a^{2}$ with $y^{n}=y_{0}^{n}$ are contained in $U \cap \alpha$ and $V \cap \beta$, respectively. Finally choose $b>0$ so that

$$
\begin{gathered}
0<b<\frac{c s a^{n-1} \log (1+\varepsilon)}{2 \pi}, \\
\overline{C_{x_{0}}(a, b)}-\left\{x^{n}=x_{0}^{n}\right\} \subset E, \quad \overline{C_{y_{0}}(a, b)}-\left\{y^{n}=y_{0}^{n}\right\} \subset E
\end{gathered}
$$

and

$$
\overline{C_{x_{0}}(a, b)} \cap \overline{C_{y_{0}}(a, b)}=\varnothing .
$$

Now take a bisecting surface $\gamma$ of $(E, \alpha, \beta)$ subject to the requirements

$$
\gamma \cap\left(C_{x_{0}}(a, b) \cup C_{y_{0}}(a, b)\right)=\varnothing
$$

and

$$
\left.\gamma \supset\left[\overline{C_{x_{0}}(a, b)} \cap\left\{x^{n}=x_{0}^{n}+b\right\}\right] \cup \overline{C_{y_{0}}(a, b)} \cap\left\{y^{n}=y_{0}^{n}+b\right\}\right] .
$$

Let $w^{\prime}$ (resp. $\left.w^{\prime \prime}\right)$ be the harmonic measure of $\gamma$ (resp. $\beta$ ) with respect to $E^{\prime}$ (resp. $\left.E^{\prime \prime}\right)$. Since $E^{\prime} \supset C_{x_{0}}(a, b)$, by using (7) and (8) we obtain

$$
D_{E^{\prime}}\left(w^{\prime}\right)>D_{C_{x_{0}}(a, b)}\left(w^{\prime}\right) \geqq c D_{C_{x_{0}}(a, b)}^{e}\left(w^{\prime}\right) .
$$

Hence by using (6) and (9) we have

$$
\frac{2 \pi}{D_{E^{\prime}}\left(w^{\prime}\right)}<\log (1+\varepsilon)
$$

and in view of (2) we conclude that

$$
\bmod \left(E^{\prime}, \alpha, \gamma\right)<1+\varepsilon .
$$

A similar consideration for $E^{\prime \prime}$ establishes (4). 


\section{REFERENCES}

1. T. Akaza and T. Kuroda, Module of annulus, Nagoya Math. J. 18 (1961), 37-41.

2. M. Glasner, Harmonic functions with prescribed boundary behavior in Riemannian spaces, Doctoral dissertation, University of California, Los Angeles, 1966.

3. M. Nakai and L. Sario, Classification theory (monograph, to appear).

4. K. Noshiro, Open Riemann surface with null boundary, Nagoya Math. J. 3 (1951), 73-79.

5. L. Sario, Modular criteria on Riemann surfaces, Duke Math. J. 20 (1953), 279-286. 6. - Classification of locally Euclidean spaces, Nagoya Math. J. 25 (1965), 87111.

7. S. Smith, Classification of Riemannian spaces, Doctoral dissertation, University of California, Los Angeles, 1965.

Received March 17, 1967. Moses Glasner's work was done partly while he was an NSF fellow. Mitsuru Nakai's work was sponsored in part by the U.S. Army Research Office-Durham, Grant DA-AROD-31-124-G855.

UNiversity of CAlifornia, Los ANGeles aNd

NAGOYA UNIVERSITY 



\section{PACIFIC JOURNAL OF MATHEMATICS}

\section{EDITORS}

\author{
H. ROYDEN \\ Stanford University \\ Stanford, California
}

\author{
J. P. JANS \\ University of Washington \\ Seattle, Washington 98105
}

J. DugundJI

Department of Mathematics

Rice University

Houston, Texas 77001

RICHARD ARENS

University of California

Los Angeles, California 90024

\section{ASSOCIATE EDITORS}
E. F. BECKENBACH
B. H. NeumanN
F. WOLF
K. YOSIDA

\section{SUPPORTING INSTITUTIONS}

\author{
UNIVERSITY OF BRITISH COLUMBIA \\ CALIFORNIA INSTITUTE OF TECHNOLOGY \\ UNIVERSITY OF CALIFORNIA \\ MONTANA STATE UNIVERSITY \\ UNIVERSITY OF NEVADA \\ NEW MEXICO STATE UNIVERSITY \\ OREGON STATE UNIVERSITY \\ UNIVERSITY OF OREGON \\ OSAKA UNIVERSITY \\ UNIVERSITY OF SOUTHERN CALIFORNIA
}

\author{
STANFORD UNIVERSITY \\ UNIVERSITY OF TOKYO \\ UNIVERSITY OF UTAH \\ WASHINGTON STATE UNIVERSITY \\ UNIVERSITY OF WASHINGTON \\ AMERICAN MATHEMATICAL SOCIETY \\ CHEVRON RESEARCH CORPORATION \\ TRW SYSTEMS \\ NAVAL ORDNANCE TEST STATION
}

\footnotetext{
Mathematical papers intended for publication in the Pacific Journal of Mathematics should be in typed form or offset-reproduced, double spaced with large margins. Underline Greek letters in red, German in green, and script in blue. The first paragraph or two must be capable of being used separately as a synopsis of the entire paper. It should not contain references to the bibliography. Manuscripts may be sent to any one of the four editors. All other communications to the editors should be addressed to the managing editor, Richard Arens, University of California, Los Angeles, California 90024.

Each author of each article receives 50 reprints free of charge; additional copies may be obtained at cost in multiples of 50 .

The Pacific Journal of Mathematics is published monthly. Effective with Volume 16 the price per volume (3 numbers) is $\$ 8.00$; single issues, $\$ 3.00$. Special price for current issues to individual faculty members of supporting institutions and to individual members of the American Mathematical Society: $\$ 4.00$ per volume; single issues $\$ 1.50$. Back numbers are available.

Subscriptions, orders for back numbers, and changes of address should be sent to Pacific Journal of Mathematics, 103 Highland Boulevard, Berkeley 8, California.

Printed at Kokusai Bunken Insatsusha (International Academic Printing Co., Ltd.), 7-17, Fujimi 2-chome, Chiyoda-ku, Tokyo, Japan.

PUBLISHED BY PACIFIC JOURNAL OF MATHEMATICS, A NON-PROFIT CORPORATION

The Supporting Institutions listed above contribute to the cost of publication of this Journal, but they are not owners of publishers and have no responsibility for its content or policies.
} 


\section{Pacific Journal of Mathematics}

\section{Vol. 24, No. $3 \quad$ July, 1968}

Duane W. Bailey, On symmetry in certain group algebras ............ 413

Lawrence Peter Belluce and Surender Kumar Jain, Prime rings with a one-sided ideal satisfying a polynomial identity ................ 421

L. Carlitz, A note on certain biorthogonal polynomials ............. 425

Charles O. Christenson and Richard Paul Osborne, Pointlike subsets of a manifold ......................................... 431

Russell James Egbert, Products and quotients of probabilistic metric

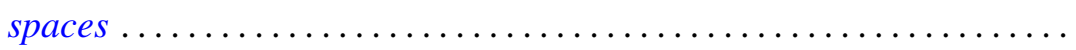

Moses Glasner, Richard Emanuel Katz and Mitsuru Nakai, Bisection into small annuli ..................................... 457

Karl Edwin Gustafson, A note on left multiplication of semigroup

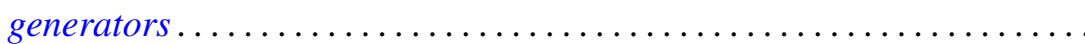

I. Martin (Irving) Isaacs and Donald Steven Passman, A characterization of groups in terms of the degrees of their characters. II ............. 467

Howard Wilson Lambert and Richard Benjamin Sher, Point-like

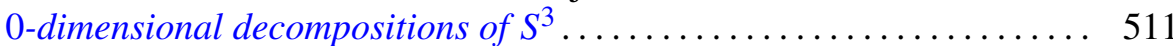

Oscar Tivis Nelson, Subdirect decompositions of lattices of width two ..... 519

Ralph Tyrrell Rockafellar, Integrals which are convex functionals . . . . . . . 525

James McLean Sloss, Reflection laws of systems of second order elliptic differential equations in two independent variables with constant coefficients ...

Bui An Ton, Nonlinear elliptic convolution equations of Wiener-Hopf type in a bounded region

Daniel Eliot Wulbert, Some complemented function spaces in $C(X)$

Zvi Ziegler, On the characterization of measures of the cone dual to a generalized convexity cone. 